\title{
PEMERTAHANAN BAHASA SUNDA PADA LINGKUNGAN ETNIS SASAK DI DESA SENGGIGI KECAMATAN BATU LAYAR KABUPATEN LOMBOK BARAT
}

\author{
Ahyati Kurniamala Niswariyana dan Nina \\ Program Studi Pendidikan Bahasa dan Sastra Indonesia \\ FKIP Universitas Muhammadiyah Mataram
}

\begin{abstract}
Abstrak
Geliat pariwisata yang kian eksis pada daerah wisata Senggigi Kabupaten Lombok Barat berdampak pada semakin terbukanya lapangan kerja, baik bagi masyarakat asli sasak tak terkecuali pula masyarakat Jawa Barat. Para pekerja yang datang dari Jawa Barat berkomunikasi dengan Bahasa Indonesia dan Bahasa Sunda. Mereka memilih untuk tinggal berkelompok sesama Orang Sunda, yang secara otomatis akan menggunakan Bahasa Sunda untuk bekomunikasi sehari-hari. Bahkan tempat tersebut telah dijuluki Kampung Sunda. Bahasa Sunda sudah mendominasi Bahasa Sasak di tempat itu, yang notabene Bahasa Sasak merupakan bahasa daerah orang Lombok. Orang-orang Lombok yang berada di lingkungan tersebut seakan-akan lebih bangga menggunakan Bahasa Sunda daripada Bahasa Sasak.

Berdasarkan pemaparan di atas, tujuan penelitian ini adalah untuk memahami bentuk eksistensi Bahasa Sunda pada Lingkungan Etnis Sasak di Desa Senggigi Kecamatan Batu Layar Kabupaten Lombok Barat serta faktor yang menyebabkan Orang Lombok di lingkungan itu lebih suka menggunakan Bahasa Sunda daripada Bahasa Sasak. Untuk memahami hal tersebut diperlukan metode penelitian yakni metode wawancara dengan teknik catat rekam.

Berdasaran hasil penelitian di lapangan didapatkan hasil bahwasanya Bahasa Sunda yang dikuasai oleh orang Sasak masih pada tataran sederhana seperti kata-kata sapaan biasa. Meskipun tidak menutup kemungkinan orang-orang Sasak yang senantiasa berinteraksi dengan orang Sunda akan menguasai Bahasa Sunda secara baik pada tataran sulit, namun sementara ini kata-kata yang kerap diucapkan berkisar pada kata-kata seperti, eta mah, ieu, hatur nuhun, sami-sami, kadie, didie, naon, kumaha, aing, abdi, aya-aya wae, bogoh, teteh, akang, aa, eceu,sabaraha, dan beberapa kata sederhana lainnya.
\end{abstract}

Kata kunci : penggunaan bahasa (Sunda), kelompok masyarakat (Sasak dan Sunda)

\section{PENDAHULUAN}

Manusia merupakan makhluk sosial yang senantiasa berinteraksi satu dengan yang lainnya. Manusia berinteraksi menggunakan bahasa, yang dalam keseharian berkomunikasi menggunakan bahasa lisan. Bloomfield menggambarkan bahwa bahasa adalah sistem lambang berupa bunyi yang bersifat sewenang- wenang (arbitrer) yang dipakai oleh anggota-anggota masyarakat untuk saling berhubungan dan berinteraksi (Sumarsono, 2012:18). Masyarakat Indonesia pada forum-forum resmi menggunakan Bahasa Indonesia untuk berkomunikasi, namun dalam situasi tak resmi masyarakat Indonesia tak luput pula menggunakan bahasa daerah untuk berkomunikasi 
terlebih jika lawan bicara berasal dari daerah yang sama. Tak dipungkiri bahwa bahasa daerah memiliki eksistensi tersendiri bagi penggunanya, apalagi jika daerah tersebut adalah daerah yang cukup terkenal, seperti Jakarta, Bandung, Jawa, dan Bali, orang-orang seakan berlomba untuk belajar menguasainya.

Bahasa Sunda merupakan bahasa daerah masyarakat tatar Pasundan di Jawa Barat. Akhir-akhir ini Bahasa dan dialek Sunda cukup familiar di telinga masyarakat Indonesia, dikarenakan beberapa tayangan lakon di televisi mengangkat budaya Jawa Barat tersebut. Bahasa-bahasa Sunda yang sering didengar diantaranya, atuh, eceu, punten, hatur nuhun, akang, dan teteh.

Senggigi merupakan salah satu destinasi wisata di Lombok. Senggigi terletak di bagian barat Pulau Lombok. Kawasan wisata Senggigi terkenal akan pantai dengan lautnya yang tenang, tak ketinggalan pula panorama bebukitan dengan tebing-tebing nan indah. Banyak sekali wisatawan yang berkunjung ke Senggigi baik wisatawan lokal maupun asing. Tak sedikit dari mereka yang pada akhirnya memilih tinggal dan menetap di Senggigi. Sejak dibukanya Senggigi sebagai daerah wisata, mengakibatkan menjamurnya tempat usaha seperti kafe, pub, diskotik, restaurant, hotel, serta artshop-artshop, hal ini berdampak pada kebutuhan pekerja. Pekerja-pekerja di kawasan wisata Senggigi tak hanya berasal dari Desa Senggigi dan wilayah Lombok saja, akan tetapi berasal dari berbagai daerah di Indonesia, diantaranya Bali, Jakarta, Bandung, Surabaya, Sumbawa, Bima, serta beberapa daerah lainnya. Di antara pendatang yang bekerja di Senggigi didominasi oleh orang Jawa Barat yang berjumlah sekitar 400 orang lebih. Mereka ada yang tinggal di mess yang telah disedikan tempat mereka bekerja, namun tak sedikit pula yang memilih mengotrak di rumah penduduk setempat. Para pekerja yang berasal dari daerah Sunda tersebut lebih "nyaman" berkomunikasi dengan bahasa Sunda dengan sesama teman seasalnya. Akibatnya orang-orang yang kerap berinteraksi dengan mereka seperti asisten kebersihan di mess, rekan-rekan di lingkungan kerja, hingga penduduk asli Lombok yang notabene menggunakan Bahasa Sasak sebagai bahasa daerahnya pun ikut menggunakan Bahasa Sunda untuk sekedar menyapa ataupun mengobrol dengan mereka.

Bahasa Sunda sebagaimana juga Bahasa Inggris cukup dikenal di kawasan wisata Senggigi, tidak menutup kemungkinan akan menjadi bahasa selanjutnya yang perlu dipelajari bagi masyarakat Senggigi khususnya. Ada 
beberapa diantara masyarakat Sasak yang akhirnya menikah dengan orang Sunda. Selaras dengan pendapat Krashen dalam Nurhadi yang menyatakan bahwa orang dewasa mempunyai dua macam cara memperoleh bahasa kedua yakni dengan cara pemerolehan dan melalui pembelajaran (2010:18). Jadi penggunaan Bahasa Sunda pada kelompok masyarakat Sasak ini termasuk dalam pembelajaran bahasa kedua.

Berdasarkan pemaparan di atas, hal yang ingin bahas dalam penelitian ini adalah bagaimanakah penggunaan Bahasa Sunda oleh orang Lombok, kata apa sajakah yang mendominasi, serta tujuan penggunaan Bahasa Sunda dalam berinteraksi dengan orang Sunda.

\section{METODE PENELITIAN}

Metode yang digunakan dalam penelitian ini ialah metode simak catat. Disebut metode simak sebab cara yang digunakan dalam memperoleh data dilakukan dengan cara menyimak penggunaan bahasa (Mahsun, 2005:90). Istilah menyimak di sini hanya berkaitan dengan penggunaan bahasa lisan oleh penutur. Sedangkan metode catat dimaksud di sini yakni peneliti mencatat kembali hasil simak yang telah diperoleh sebelumnya. Teknik analisis data dalam penelitian ini adalah peneliti mengambil beberapa sampel yang diambil dari hasil wawancara dengan orang asli Lombok yang bisa berbahasa Sunda serta hasil dari merekam percakapan yang terjadi antara orang Lombok dengan orang Sunda. Selanjutnya peneliti menggunakan teknik catat untuk mencatat kembali data yang diperoleh untuk kemudian dianalisis.

Setelah melalui proses catat, peneliti melakukan pengelompokan data, di mana data-data yang diperoleh tersebut dipilah antara yang masuk kategori pengaruh ke bahasa serta pengaruh ke pendidikan karakter. Selanjutnya barulah peneliti menguraikan data-data tersebut dalam bentuk narasi.

\section{HASIL DAN PEMBAHASAN}

KORPUS 1(Responden 1: Nina, Responden 2: Sapri Ali alias Papi Ali; Selasa 28 November 2017 pukul 11.00 WITA; Tempat: kos papi Ali di desa Senggigi; Identitas sample, Nama: Sapri Ali TTL: Jantuk, 10-01-1985 Alamat: Jantuk, Mantang-Batukliang Lombok Tengah)

\section{Transkrip Percakapan 1}

- Responden 2: sami bagi saya, saya mau bergaul ke kiri ke atas ke bawah sama dan segi itu juga bukan bangga atau pede misalnya Bahasa Sunda ini terus semaumaunya ngomong sia sia aing aing itu kan ga pantes ya sesama pergaulan lepas bebas bisa berbahasa seperti itu tapi bahasa aing sia tidak pernah saya ucapkan. (Sunda: sami $=$ sama, sia $=$ kamu, aing $=$ saya) 
- Responden 2: Boleh lihat yang jualan es jualan seblak kadang saya beli, A timana A? ti Bandung, Bandung timana? Nah dari situ komunikasinya keluar kita pakai bahasa mereka sehari-hari gitu. (Sunda: A ti mana? Ti Bandung = kamu berasal dari kota mana? Dari Bandung. Bandung ti mana? = bagian mana Bandungnya?)

- Responden 1: Haturnuhun akang bantosanna. (Sunda: hatur nuhun = terima kasih, akang = sebutan kakak laki-laki, bantosanna = bantuannya)

- Responden 2: Muhun sami-sami. (Sunda: muhun $=$ iya, sami-sami $=$ sama-sama)

Pada Korfus 1 terjadi dialog antara Responden 1 (Nina) dengan Responden 2 (papi Ali), di mana responden 1 menanyakan latar belakang responden 2 bisa berbahasa Sunda yang notabene ia asli orang Lombok. Dari percakapan tersebut dapat diketahui bahwa Bahasa Sunda yang diucapkan oleh responden 2 masih sebatas bahasa sapaan sederhana seperti hatur nuhun, bantosanna, sami-sami, ti mana, aing, sia ,aa, asa, abdi. Responden 2 lebih banyak menggunakan Bahasa Indonesia untuk berkomunikasi dengan lawan bicara meski tahu bahwa lawan bicaranya adalah orang Sunda.

Korfus 2 (Responden 1: Johan alias om Jo, Responden 2: Nina, Responden 3: mba yang dirias; Waktu : 17.00 WITA, Tempat: Mess; Identitas sample, Nama: Junaedi alias Johan alias Joe, TTL: Batulayar, 02-
04-1972, Alamat: Ds Loco Desa Senggigi

Kec Batulayar Lombok Barat).

Transkripsi percakapan 2

- Responden 1: Ndak banyak bisa bahasa Sunda, terus rek naon kadie? (Sunda: rek naon kadie = mau apa kesini?)

- Responden 1: Seminar naon eta? (Sunda: naon eta=apa itu)

- Responden 1: Bahasa naon? Bahasa Dompu? (Sunda: naon = apa)

- Responden 2: Ya semua bahasa sih $s a$-Indonesia. (Sunda: sa- $^{=} \mathrm{se}-=$ seluruh)

- Responden 3: Kabeh bahasa om Jo (Sunda: kabeh = semua)

- Responden 1: Kalau ga bisa rek naon atuh kadie? (Sunda: rek naon kadie? = untuk apa kesini?)

- Responden 1: Terus dikumahakeun pami engeus dapat rekaman ieu (Sunda: dikumahakeun = dibuat apa, pami $=$ kalau, engeus $=$ sudah, ieu = ini. Pada kalimat ini memiliki makna apa yang akan kamu lakukan setelah selesai merekam?.

- Responden 1: Tapi bahasa Bandung na bisa saeutik (Sunda: saeutik = sedikit)

- Responden 2: Om Jo meni pinter bikin alis (Sunda: meni $=$ sangat)

- Responden 1: Masa sih, aya kabogohna teu neng? (Sunda: aya = ada, kabogoh = pacar, teu = tidak, neng $=$ sebutan untuk anak perempuan). Pada kalimat ini memiliki makna apa sudah punya pacar belum de?)

- Responden 2: Boga atuh (Sunda: boga $=$ punya, atuh $=$ dong)

- Responden 3: He'eh maneh teh bang jo (Sunda=he'eh artinya iya, maneh artinya kamu)

- Responden 1: Naon sia meni (Sunda: naon sia meni $=$ apa kamu,,terlalu)

- Responden 3: Maneh sia, sing bener nyieun na, nyieun halis na 
(Sunda: maneh=kamu [kasar], sia $=$ kamu [kasar sekali], nyieun $=$ buat, halis = alis). Pada kalimat ini memiliki makna kamu yang bener buat alisnya.

- Responden 1: Pasti alus atuh neng pasti jiga artis, artis digusur (Sunda: Pasti alus atuh neng pasti jiga artis, artis digusur= Pasti bagus donk neng, tapi seperti artis yang digusur)

- Responden 3: Digusur naon? (Sunda: Digusur naon? Apanya yang digusur?)

- Responden 1: Eta halis na jiga artis digusur (Sunda: eta = itu, halis na $=$ alisnya, jiga artis $=$ seperti artis. Pada kalimat ini memiliki makna itu alis seperti artis yang digusur oleh satpol pp.

Percakapan yang terjadi pada korfus 2 antara peneliti (responden 2) dengan responden 1 (Johan/ Om Jo ialah orang Lombok yang bisa berbahasa Sunda) dan responden 3 (mba yang dirias ialah orang Sunda yang bekerja di Lombok). Dari percakapan di atas penggunaan Bahasa Sunda cukup banyak seperti: rek naon kadie, naon eta, naon, rek naon atuh kadie, he'eh, maneh, sa, atuh, neng, aya kabogohna teu neng, Naon sia meni, pasti alus atuh neng pasti jiga, Eta halis na jiga artis. Topik pada pembicaraan ini adalah reseponden 1 menjelaskan bahwa dia tidak tll fasih menggunakan bahasa sunda tapi dia berusaha menggunakan bahasa sunda pada responden 3 karena berasal dari etnis sunda agar responden 3 tetap memilih responden 1 merias wajahnya untuk 3 bulan kedepan

Korfus 3 (Responden 1: Hidayatul ilmi alias Ida, TTL: 23-05-1980 sumbawa, Alamat: Sengkol Kec. Pujut Lombok Tengah; Responden 2: Ririn Ria Hartini, TTL: Keruak, 20-02-1993, Alamat: Kayu putih 002/003 Tempos Gerung Lombok Barat, Responden 3: Yanti, Waktu: Kamis 30 November 201720.00 WITA, Tempat: Kost ida).

Transkripsi percakapan 3

- Responden 2: Beli Epicentrum, beli di epicentrum teteh bilang (Sunda: teteh $=$ sebutan kakak perempuan)

- Responden 1: Naon atuh....? (jeda difoto) eh senengnya kalau difoto (Sunda: naon atuh $=$ dong?)

- Responden 2: Di Epicentrum teteh bilang, coba. (Sunda: teteh = sebutan untuk kakak perempuan)

- Responden 1: Beli dimana? Sabaraha? (Sunda: sabaraha = berapa harganya?)

- Responden 2: Sabaraha ieu? (Sunda: sabaraha $=$ berapa, ieu $=$ ini). Jadi kalimat ini memiliki makna berapa harganya?

- Responden 1: Sabaraha? (Sunda: sabaraha $=$ berapa)

- Responden 2: Apa itu sabaraha? (Sunda: sabaraha = berapa). Kalimat tersebut memiliki makna mempertanyakan arti dari kata sabaraha.

- Responden 1: Ah kau ngaku-ngaku cewek Bandung sana sini tapi ga ngerti sabaraha dasar belegug. (Sunda: dasar belegug $=$ dasar bodoh)

- Responden 2: Sabaraha,,,sabaraha lieur aing hehhee. (Sunda: lieur = pusing, aing = saya) 
- Responden 3: Ape lah side ngeraos? (Sasak=kamu ngomong apa?)

Pada korfus 3, peneliti hanya bertindak sebagai perekam percakapan yang terjadi antara responden 1 dengan responden 2 yang keduanya asli orang Lombok, etnis Sasak. Beberapa kata Bahasa Sunda yang diucapkan yakni naon atuh, teteh, sabaraha, sabaraha ieu, lieur, belegug, aing. Pada percakapan ini kedua responden berusaha menggunakan bahasa sunda agar dianggap asli orang sunda oleh teman atau orang yang baru dikenal

Korfus 4 (Responden 1: Nina, Responden 2: H. Muhammad Zarikasyi, S.P, TTL: Gerung, 22-05-1985, Alamat: Ds Mesanggok 007 Mesanggok Gerung Lombok Barat, Waktu: Jumat 1 desember 2017, Tempat: Portal BTN Grand Valley Senggigi).

Transkripsi percakapan 4

- Responden 2: Kata-kata pertama Sunda yang saya minta ajarin adalah I LOVE YOU " Abdi Bogoh Ka Anjeun”. (Sunda: abdi = saya, bogoh = cinta, anjeun = kamu)

- Responden 2: Mitoha alias mertua. Sama mertua biasanya nanya "A $a$ nuju naon?" saya jawab "nији ngagoler", "tos tuang? Ya itulah kata-kata dasar untuk sehari-hari. (Sunda: aa = sebutan untuk kakak laki-laki, nuju = sedang melakukan aktifitas, naon $=$ apa, tos $=$ sudah, tuang $=$ makan)

- Responden 1: Terus naon deui? (Sunda: terus naon deui $=$ apa lagi?)
- Responden 2: Bade ngiring moal? (sunda: bade $=$ mau, ngiring $=$ ikut, moal $=$ tidak $)$

- Responden 1: Hatur nuhun ji (Sunda: hatu nuhun = terimakasih)

- Responden 2: Sami-sami teh (Sunda: sami-sami = sama-sama, teh $=$ sebutan untuk kakak perempuan)

- Responden 1: Iya sawangsulna (Sunda $=$ kembali kasih $)$

Pada korfus 4 terjadi wawancara antara peneliti (responden 1) dengan responden 2 (Haji Zarkasy). Responden 2 merupakan orang Sasak asli yang kemudian menikah dengan orang Sunda, belajar Bahasa Sunda dari pergaulan dan istri. Bahasa Sunda yang diucapkan oleh responden 2 diantaranya ialah, abdi bogoh ka anjeun, mitoha, aа nuju naon, nuju ngagoler, tos tuang, bade ngiring moal, sami-sami teh.

Korfus 5 (Responden 1: Bi Niah, TTL: Batulayar, 22-05-1987, Alamat: Kampung Loco Desa Senggigi Kec. Batulayar, Responden 2: Melati, Responden 3: Mawar (Responden tidak mau dipublikasi namanya), Waktu: kamis, 16.00 WITA, Tempat: Mess Paragon).

Transkripsi percakapan 5.

- Responden 1: Goreng teloq (Sasak: teloq $=$ telur)

- Responden 2: Goreng endog (Sunda: endog $=$ telur)

- Responden 3: Goreng teloq mun didie mah (Sunda: mun = kalau, didie $=$ disini, mah $=$ pelengkap dalam bahasa Sunda)

- Responden 1: Goreng endog (Sunda: goreng endog $=$ goreng telur) 
- Responden 2: Tah kitu (Sunda: tah $=$ itu, kitu $=$ seperti itu)

- Responden 1: Kumaha deui atuh heheheehe, diem di sini (Sunda: kumaha $=$ bagaimana, deui $=$ lagi, atuh $=$ dong)

- Responden 3: Cengek na kirang loba, rek dicengekan deui moal? (Sunda: cengek $=$ cabe rawit, na $=$ nya, kirang $=$ kurang, loba $=$ banyak, rek $=$ mau, dicengekan deui moal $=$ ditambah cabenya tidak?)

- Responden 2: Nya sok meh teu sebel! (Sunda: nya sok = silakan, meh $=$ agar, teu $=$ tidak, sebel $=$ mual)

- Responden 1: Naon deui atuh? (Sunda: naon $=$ apa, deui $=$ lagi, atuh $=$ donk)

- Responden 3: Vetcin na engges acan? (Sunda: vetcin na = vetcinnya, engges $=$ sudah, encan = belum)

- Responden 3: Rek jeung naon sangunna? Aya keneh nasi kuning can haseum da. (Sunda: rek = mau, jeung $=$ dengan, naon =apa, sanguna $=$ nasinya, aya $=$ ada, keneh, masih, can = belum, hasem $=$ basi, $\mathrm{da}=$ kata pelengkap dalam bahasa Sunda)

- Responden 2: nu mana-mana weh, burukeun geus lapar! (Sunda: nu = yang, mana-mana weh = mana saja, burukeun $=$ cepetan, geus $=$ sudah)

- Responden 1: wah (Sasak=sudah)

- Responden 3: wah (Sasak=sudah)

- Responden 1: wah toloan sie (Sasak: sudah dimasukkan garam ?)

- Responden 2: Garem!

- Responden 3: (sambil mengambil wajan) Dimana sih ah susuk teh (Sunda: susuk = alat memasak, teh = kata tambahan dalam bahasa Sunda)

- Responden 2: Burukeun atuh (Sunda: burukeun $=$ cepat, atuh $=$ dong)
Pada korfus 5 peneliti hanya merekam percakapan yang terjadi antara responden 1, 2, dan 3 yang mana responden 1 adalah orang asli etnis Sasak yang bertugas sebagai asisten di mess tersebut, sedangakan responden 2 dan 3 adalah orang Sunda. Kata-kata Sunda yang diucapkan responden 1 ialah endog, Kumaha deui atuh, Naon deui atuh, aya, keneh, meh, teu sebel, cengek, engges can, sangu, hasem, burukeun. Pada korfus 5 terjadi percakapan antara orang sunda dan sasak, keduanya saling mempelajari bahasa agar lebih akrab. Orang Sunda mempelajari bahasa Sasak dan sebaliknya orang Sasak mempelajari bahasa Sunda.

Korfus 6 ( Responden 1: Istri H Jack,

Responden 2: H. Jack, Waktu: Jumat 01

Desember 2017, Tempat: Rumah H Jack).

Transkripsi percakapan 6

- Responden 1: Ti mana pak? (Sunda: $\mathrm{ti}=$ dari)

- Responden 1: Bade iraha rek muludan pak. (Sunda: bade = mau, iraha $=$ kapan, rek $=$ mau, muludan = bulan maulid)

- Responden 2: engkin geulis (Sunda: engkin $=$ nanti, geulis $=$ cantik)

- Responden 1: Ah..panya teh (Sunda: panya $=$ saya kira, teh $=$ kata pelengkap dalam bahasa Sunda)

- Responden 2: Ndek araq kepeng geulis (Sasak: belum punya uang, Sunda: geulis $=$ cantik)

- Responden 1: Muhun, taun baruan di Puncak nya pah (Sunda: muhun = iya, taun = tahun baruan = baru, kalimat tersebut memiliki makna 
mengajak acara tahun baru di puncak)

- Responden 2: Engkin ku papah ditelepon, bun aya pulsa lima rebu teu kirim atuh ka papah, ndek araq pulse tanggal toaq niki (Sunda: engkin $=$ nanti, $\mathrm{ku}=$ oleh, aya $=$ ada, rebu $=$ ribu, teu $=$ tidak, atuh $=$ dong, $\mathrm{ka}=\mathrm{ke})$. (Sasak: ndek = tidak, araq $=$ tidak, pulse $=$ pulsa, toaq $=$ tua, niki $=$ ini). Pada kalimat ini memiliki makna minta pulsa lima ribu karena tidak punya uang nanti saya ganti.

- Responden 1: Mit-amit si papah mah. Bunda nembe gaduh icis tina endrose tos seep deui (Sunda: mitamit si papah mah = sangat menyebalkan papah ini, nembe $=$ baru saja, gaduh = punya, icis = uang, tina $=$ dari, endrose adalah orang mempromosikan produk instagram, tos $=$ sudah, seep $=$ habis, deui = lagi). Pada kalimat ini memiliki makna suaminya menyebalkan karena sang istri baru punya uang sedikit sudah habis lagi.

- Responden 2: Engkin digentosan bun. (Sunda: engkin=nanti, digentosan=diganti)

- Responden 1: Ah ti kapungkur digentosan tapi mana atuh (Sunda: $\mathrm{ti}=$ dari, kapungkur $=$ dulu, digentosan $=$ diganti). Kalimat ini memiliki makna dari dulu mau diganti tapi tidak ada buktinya.

- Responden 2: Hus entos ah meni itungan (Sunda: entos = sudah, meni $=$ sangat, itungan $=$ hitungan) . Pada kalimat ini memiliki makna tidak boleh hitung-hitungan dengan suami.

- Responden 1: Artos istri nu istri artos pameget nu istri pah (Sunda: artos istri $=$ uang istri, pameget $=$ suami, nu = milik). Pada kalimat ini memilili makna uang istri tetap uang istri tapi uang suami punya istri.

- Responden 2: Hus ah ieu papah keur ngarekam jang penelitian teh nina (Sunda: ieu $=$ ini, keur $=$ sedang, ngarekam = merekam, jang = untuk). Pada kalimat ini memiliki makna sudah jangan bicara lagi, papah sedang merekam percakapan kita untuk penelitian teh nina.

- Responden 1: Teh nina mana teu wawuh, tos pareman isin ah. Enggalkeun pah sok ngisinkeun. (Sunda: teu wawuh = tidak kenal, tos = sudah, pareman = matikan, isin $=$ malu, enggalkeun = cepat, ngisinkeun $=$ memalukan. Pada kalimat ini memiliki makna Teh Nina siapa? Saya tidak kenal. Cepat matikan bikin malu aja, cepat pah bikin malu saja.

Pada korfus 6 terjadi percakapan antara suami (haji Jack) yakni orang Lombok dan istrinya yang merupakan orang Sunda. Kata-kata Bahasa Sunda yang diucapkan Haji Jack diantaranya: engkin geulis, engkin ku papah ditelepon, bun aya pulsa lima rebu teu kirim atuh ka papah, nembe, gaduh icis, engkin digentosan, seep, hus entos ah meni itungan, hus ah ieu papah keur ngarekam jang penelitian teh nina. Pada percakapan ini kedua responden menggunakan bahasa Sunda karena ingin perbincangan mereka tidak diketahui oleh adik iparnya responden 2 yang notabennya asli suku Sasak karena responden 2 mau meminta pulsa di depan adik iparnya Korfus 7 (Responden 1: Nina, Responden 2: Siti Aminah, TTL: Babakan Timur 22- 
12-1984, Alamat: Babakan Timur $001 \mathrm{Kel}$

Babakan Kec Sandubaya Kota Mataram,

Responden 3: Anisah Yulianti alias Teh

Deni, Waktu: 19.00 WITA, Tempat:

Warung Teh Deni).

Transkripsi percakapan 7

- Responden 2: Ieu KTP (Sunda: ieu = ini)

- Responden 2: Encan, tadi rek solat dititah ka warung meni reuwas aya naon (Sunda: encan $=$ belum, rek = mau, dititah $=$ disuruh, meni $=$ sangat, reuwas $=$ kaget, aya $=$ ada, naon $=$ apa). Pada kalimat ini adalah niatnya mau solat tapi saya kaget karena tiba-tiba disuruh ke warung.

- Responden 3: Nginjem heula KTP aya perlu (Sunda: nginjem = pinjam, heula $=$ dulu, aya $=$ ada, perlu $=$ urusan). Pada kalimat ini memiliki makna pinjam KTP dulu sebentar karena ada perlu.

- Responden 3: Ini mah orang dieu orang Lombok (Sunda: orang dieu = saya asli orang Lombok)

- Responden 2: Tah ieu sesa nu kamari buru teh encan solat isya. (Sunda: tah ieu $=$ ini, sesa $=$ sisa, nu kamari $=$ yang kemarin, buru= cepat, encan = belum). Pada kalimat ini memiliki makna ini adalah sisa uang kemarin, saya mau pulang karena belum solat isya.

- Responden 3: Engke heula KTP na can dipoto. Keula sakeudap. (Sunda: engke heula = tunggu dulu, can dipoto = belum difoto, keula sakeudap = tunggu sebentar)

- Responden 1: Nya sok weh ngobrol biasa (Sunda: nya sok weh = silakan kita ngobrol seperti biasa saja)

- Responden 3: Keun weh moal aya nu ngartieun, kur butuh obrolan urang nu alami, Cuma gitu doang.
(Sunda: keun weh = biarkan saja, moal $=$ tidak, aya $=$ ada, $n u=$ yang, ngartieun $=$ mengerti, kur = hanya, urang = kita. Pada kalimat ini memiliki makna biarkan saja karena tidak ada yang mengerti, dia membutuhkan pembicaraan yang alami.

- Responden 2: Nya entos atuh bade uih heula sakeudap. (Sunda: nya entos atuh = ya sudah, bade = ingin, uih $=$ pulang, heula $=$ dulu, sakeudap $=$ sebentar)

- Responden 3: Buru Nina ngomong nuhun. (Sunda: buru = cepat, ngomong $=$ ucapkan, nuhun $=$ terima kasih)

- Responden 1: Haturnuhun teh. (Sunda: terima kasih kak)

- Responden 2: Nya biasa weh. Tiap hari ge bahasa Sunda didie ge bahasa Sunda. (Sunda: nya biasa weh $=$ biasa saja, ge $=$ juga, didie $=$ disini). Pada kalimat ini memiliki makna setiap hari saya menggunakan bahasa Sunda.

- Responden 3: Terutama jeung saya sok aya rahasia. (Sunda: jeung = dengan, sok $=$ sering, aya $=$ ada . Pada kalimat ini memiliki makna terutama komunikasi dengan saya menggunakan bahasa Sunda karena banyak rahasia.

- Responden 2: Osok curhat. (Sunda: osok $=$ sering)

- Responden 1: Ya sudah atuh teh nya hatur nuhun (Sunda: atuh = dong, teh = sebutan untuk kakak perempuan, nya = ya). Pada kalimat ini memiliki makna baik kita cukupkan sampai sini, saya ucapkan terimakasih.

- Responden 2: Sami-sami (Sunda: sami-sami = sama-sama)

Pada korfus 7 percakapan cukup panjang terjadi antara responden 1 (Nina), responden 2 (Siti Aminah), dan responden 
3 (Teh Deni). Kedua responden berasal dari Lombok, adapun kata-kata Bahasa Sunda yang diucapkan ialah: ieu, encan, rek, dititah, ka, meni, reuwas, aya naon, nginjem heula KTP aya perlu, dieu, tah ieu sesa nu kamari buru teh encan solat isya, engke heula KTP na can poto, keula sakeudap, ieu, keur, keur urang ngobrol, keun weh moal aya nu ngartieun, kur butuh obrolan urang nu alami, nya entos atuh bade wih heula sakeudap, hatur nuhun teh, kumaha, didie, Nya seneng weh nya, jeung, aya, kitu, sok, sami-sami.

KORPUS 8 (Responden 1 : Nina, Responden 2: Mahsub alias Caconx Acox, hari: Senin 05 Desember 201, pukul 21.00 WITA, komuikasi melalui Ponsel, TTL: Sambelia, 25 tahun, Alamat: Senggigi Batulayar).

Transkrip percakapan 8.

- Responden 1: Milarian orang sasak anu bisa basa Sunda (Sunda: milarian = mencari, anu = yang, basa $=$ bahasa)

- Responden 2: He'eh aing mah asli orang Lombok Timur (Sunda: he'eh aing mah = iya saya)

- Responden 1: Hor geuning jauh. Oh iya kang mulai kapan bisa bahasa Sunda (Sunda: Hor geuning jauh = ternyata jauh ya)

- Responden 2: Aing mah bisa bahasa Sunda na mah tiga tahunan yang lalu pedah sering gabung ama orang Sunda weh. (Sunda: aing $=$ saya, pedah $=$ karena, weh $=$ saja). Pada kalimat ini memiliki makna Saya bisa bahasa Sunda sudah tiga tahun karena sering bergaul dengan orang Sunda.

- Responden 2: Eungges dahar? Si eneng geus dahar? (Sunda: eungges $=$ sudah, dahar $=$ makan, eneng $=$ sebutan untuk adik perempuan dalam bahasa Sunda, geus $=$ sudah). Pada kalimat ini memiliki makna menanyakan apakah sudah makan?.

- Responden 1: hehehehe atos tadi maulidan di Gerung. (Sunda: atos tadi $=$ sudah tadi)

- Responden 2: Iya se'er teh tapi banyak yang takut ceunah, padahal mah moal dikukumahakeun ieu nya teh? Teh dinda mah dulu yang aku catok-catok waktu di Mekar jadi kan bisa sedikit-sedikit meh orang Sunda hente bisa bodo-bodoin kita teh karena kita sudah ngerti bahasa Sunda (Sunda: se'er = banyak, ceunah = katanya, moal = tidak akan, dikukumahakeun $=$ tidak terjadi apa-apa, ieu = ini, nya = ya, teh $=$ sebutan untuk kakak perempuan, meh = agar, hente = tidak). Pada kalimat ini memiliki makna banyak yang bisa bahasa Sunda tapi mereka takut terjadi sesuatu. Dulu saya sering mencatok rambut teh dinda di mekar jadi bisa sedikit-sedikit agar tidak mudah ditipu.

- Responden 2: Papi Al mah kur bisa saeutik dia mah teu loba bahasa na, bahasa Sunda na nu kasarkasar. (Sunda: mah = kata tambahan dalam bahasa Sunda, kur $=$ hanya, saeutik $=$ sedikit, teu $=$ tidak, loba $=$ banyak, na $=$ nya, nu = yang). Pada kalimat ini memiliki makna Papi Al hanya bisa sedikit dan bahasanya kasar.

- Responden 1: Hehehe... oh iya nama akang teh siapa sih? Di facebook mah namina Acoxs $($ Sunda: namina $=$ namanya $)$ 
- Responden 2: Aing mah Lombok Timur na di Sambalia (Sunda: aing = saya, mah = kata tambahan dalam bahasa Sunda)

- Responden 1: Umur na sabaraha sih si akang teh. (Sunda: sabaraha = berapa, na $=$ nya, akang = sebutan kakak laki-laki, teh = kata tambahan dalam bahasa Sunda)

- Responden 1: Horrr anom keneh geuning (Sunda: anom $=$ masih muda, keneh $=$ masih)

- Responden 2: Padahal awalnya Cuma buat status gusti nu agung gitu kan terus teh Dinda menandai si teteh. Nanaonan ari maneh teh Dinda. Aink inbox kan ai sia kunaon, gitu kan sama dia, dia cerita ada temennya cari orang Lombok nu bisa bahasa Sunda. (Sunda: nanaonan = apa maksudnya, ari = kata tambahan dalam bahasa Sunda, maneh = kamu, ai = kata tambahan dalam bahasa Sunda, sia = kamu, kunaon = kenapa). Pada kalimat ini memiliki makna awal mulanya saya tulis di status "ya allah yang maha kuasa" tiba2 teh dinda menandai si teteh, saya inbox ke dia "kamu apa-apaan sih ga ada kerjaan, dia cerita katanya ada temannya cari orang Lombok yang bisa bahasa sunda.

- Responden 2: Ah sia mah aya-aya wae, aing bilang sia mah nu gelo, biasa weh (Sunda: sia =, aya-aya wae = ada-ada saja, gelo = gila ini ada-ada saja, aku bilang kamu itu gila)

- Responden 1: Oh lami geuning. (Sunda: lami $=$ lama, geuning $=$ ternyata)

\section{Pada Korfus 8 ini proses wawancara dilakukan melalui ponsel, yakni percakapan antara peneliti (Nina)}

dengan Mahsub alias Echy. Mahsub cukup panjang akan tetapi penggunaan Bahasa Sunda dalam berkomunikasi dengan lawan bicaranya tidak terlalu aktif, diantaranya, eta, ayeuna, mah, akang, aing, weh, naon, didie, ceunah, moal, ai, sia, kunaon, Ah sia mah aya-aya wae, aing bilang sia mah nu gelo, biasa weh, ngora keneh.

\section{SIMPULAN}

Pada dasarnya orang-orang Lombok yang berada lingkungan orang Sunda dan kerap berinteraksi dengan orang Sunda akan pelan-pelan bisa berbahasa Sunda, berawal dari sering mendengar, melihat gerakan (bahasa tubuh) orang Sunda, lambat laun akan bisa berkomunikasi menggunakan Bahasa Sunda. Pada dasarnya manusia adalah makhluk cerdas yang diciptakan oleh Allah. Manusia akan mampu beradaptasi dengan lingkungan dan orang- orang baru. Jadi dapat dikatakan bahwa Bahasa Sunda merupakan imfluence bagi pengguna Bahasa Sasak di Senggigi meskipun tidak serta merta menggeser kedudukan Bahasa Sasak sebagai tuan rumah di daerahnya sendiri, akan tetapi berdasarkan hasil temuan di atas dapat dikatakan bahwa pengaruh Bahasa Sunda pada penutur Bahasa Sasak cukup banyak. Adapun Bahasa Sunda yang dikuasai oleh orang Sasak masih pada tataran sederhana seperti kata-kata sapaan biasa. Meskipun tidak 
menutup kemungkinan orang-orang Sasak yang senantiasa berinteraksi dengan orang Sunda akan menguasai Bahasa Sunda secara sempurna. Kata-kata yang kerap diucapkan yakni, eta mah, ieu, hatur nuhun, sami-sami, kadie, didie, naon, kumaha, aing, abdi, aya-aya wae, bogoh, teteh, akang, aa, eceu.

\section{DAFTAR PUSTAKA}

Mahsun,. (2005). Metode Penelitian Bahasa. Rajawali Press:Jakarta.

Nurhadi,. (2010). Dimensi-Dimensi Belajar Bahasa Kedua. Sinar Baru Algensindo: Bandung.

Sumarsono,. (2012). Sosiolinguistik.

Pustaka Pelajar: Yogyakarta. 